Research paper

\title{
Spodium bonding and other non-covalent interactions assisted supramolecular aggregation in a new mercury(II) complex of a nicotinohydrazide derivative
}

\author{
Ghodrat Mahmoudi $^{\mathrm{a}, *}$, Ennio Zangrando ${ }^{\mathrm{b}}$, Barbara Miroslaw ${ }^{\mathrm{c}}$, Atash V. Gurbanov ${ }^{\mathrm{d}, \mathrm{e}}$, \\ Maria G. Babashkina ${ }^{f}$, Antonio Frontera ${ }^{g}$, Damir A. Safin ${ }^{\mathrm{h}, \mathrm{i}, \mathrm{j}}$ \\ ${ }^{a}$ Department of Chemistry, Faculty of Science, University of Maragheh, P.O. Box 55181-83111, Maragheh, Iran \\ ${ }^{\mathrm{b}}$ Department of Chemical and Pharmaceutical Sciences, University of Trieste, Via L. Giorgieri 1, 34127 Trieste, Italy \\ ${ }^{c}$ Department of Crystallography, Faculty of Chemistry, Maria Curie-Sklodowska University, Pl. Marii Curie-Sklodowskiej 3, 20-031 Lublin, Poland \\ d Centro de Química Estrutural, Instituto Superior Técnico, Universidade de Lisboa, Av. Rovisco Pais, 1049-001 Lisboa, Portugal \\ e Department of Chemistry, Baku State University, Z. Khalilov str. 23, AZ 1148 Baku, Azerbaijan \\ ${ }^{\mathrm{f}}$ Institute of Condensed Matter and Nanosciences, Universite Catholique de Louvain, Place L. Pasteur 1, 1348 Louvain-la-Neuve, Belgium \\ ${ }^{\mathrm{g}}$ Department of Chemistry, Universitat de les Illes Balears, Crta de Valldemossa km 7.5, 07122 Palma de Mallorca, Baleares, Spain \\ ${ }^{\mathrm{h}}$ University of Tyumen, Volodarskogo Str. 6, 625003 Tyumen, Russian Federation \\ ${ }^{\mathrm{i}}$ Kurgan State University, Sovetskaya Str. 63/4, 640020, Russian Federation \\ ${ }^{\mathrm{j}}$ Innovation Center for Chemical and Pharmaceutical Technologies, Ural Federal University named after the First President of Russia B.N. Eltsin, Mira Str. 19, \\ Ekaterinburg 620002, Russian Federation
}

\section{A R T I C L E I N F O}

\section{Keywords:}

Spodium bond

Mercury

Crystal structure

X-ray crystallography

DFT

\begin{abstract}
A B S T R A C T
In this work we report a new $\mathrm{Hg}$ (II) coordination compound $\left[\mathrm{Hg}(\mathrm{HL})(\mathrm{SCN})_{2}\right]$, which was readily obtained from a mixture of $\mathrm{Hg}(\mathrm{SCN})_{2}$ and $N^{\prime}$-(1-(pyridin-2-yl)ethylidene)nicotinohydrazide (HL). The metal cation is chelated by the organic ligand in a $N, N^{\prime}, O$ tridentate manner through the 2-Py and amide nitrogen donors, and carbonyl oxygen atom. The coordination sphere is filled by the sulfur donors of two thiocyanate anions, thus yielding a pentacoordinated geometry, which is best described as being about $64 \%$ along the pathway of distortion from the ideal square pyramidal toward trigonal bipyramidal structure. In addition, the metal center forms two types of the $\mathrm{Hg} \cdots \mathrm{N}$ spodium bonds, which are formed with the 3-Py nitrogen atom of a symmetry related molecule and with the nitrogen atom of one thiocyanate ligand of another molecular unit. These $\mathrm{Hg} \cdots \mathrm{N}$ spodium bonds enlarge the coordination environment of the metal cation in between a capped trigonal prism close to pentagonal bipyramid. In addition a 1D zig-zag-like polymeric chain is formed, which is further reinforced by bilateral $\mathrm{C}-\mathrm{H} \cdots \mathrm{O}$ hydrogen bonds. These chains are interlinked through $\mathrm{N}-\mathrm{H} \cdots \mathrm{N}$ hydrogen bonds and additionally glued by $\pi \cdots \pi$ interactions between the 2-Py rings. Thus, considering all the $\mathrm{Hg} \cdots \mathrm{N}$ spodium and $\mathrm{N}-\mathrm{H} \cdots \mathrm{N}$ hydrogen bonds, a supramolecular 2D layer is formed with a binodal 3,4-connected hcb topology. The 2D layers are interlinked through a myriad of $\pi \cdots \pi$ interactions. According to the Hirshfeld surface analysis, the crystal packing of $\left[\mathrm{Hg}(\mathrm{HL})(\mathrm{SCN})_{2}\right]$ is mainly characterized by intermolecular $\mathrm{H} \cdots \mathrm{H}, \mathrm{H} \cdots \mathrm{C}, \mathrm{H} \cdots \mathrm{N}$ and $\mathrm{H} \cdots \mathrm{S}$ contacts comprised from 15.9 to $22.3 \%$, followed by less significant $\mathrm{H} \cdots \mathrm{O}, \mathrm{C} \cdots \mathrm{C}, \mathrm{C} \cdots \mathrm{N}, \mathrm{N} \cdots \mathrm{S}$ and $\mathrm{Hg} \cdots \mathrm{N}$ contacts comprised from 2.8 to $6.3 \%$. The intermolecular $\mathrm{H} \cdots \mathrm{C}, \mathrm{H} \cdots \mathrm{N}, \mathrm{H} \cdots \mathrm{O}, \mathrm{H} \cdots \mathrm{S}$ and $\mathrm{C} \cdots \mathrm{C}$ contacts are highly favoured in the molecular surface of $\left[\mathrm{Hg}(\mathrm{HL})(\mathbf{S C N})_{2}\right]$, while the $\mathrm{N} \cdots \mathrm{S}$ contacts are less favoured, and remaining contacts are significantly impoverished. Finally, density functional theory (DFT) calculations at the PBE0/def2-TZVP level of theory have been used to evaluate and characterize the $\mathrm{Hg} \cdots \mathrm{N}$ spodium bonds, including molecular electrostatic potential (MEP), quantum theory of atoms in molecules (QTAIM) and noncovalent interaction plot (NCIPlot) computational tools.
\end{abstract}

\footnotetext{
* Corresponding author at: Department of Chemistry, Faculty of Science, University of Maragheh, P.O. Box 55181-83111, Maragheh, Iran.

E-mail address: ghodratmahmoudi@gmail.com (G. Mahmoudi).
} 


\section{Introduction}

Nowadays, non-covalent interactions are of great interest and have attracted a particular interest from researchers due to their crucial role in many fields of chemistry [1-4]. These interactions are responsible for the formation of a molecular cluster from either atoms or parent molecules without formation or breaking of covalent bonds. Non-covalent interactions were first discovered by J.D. van der Waals [5] and their importance in living beings is clearly manifested by the double helix structure of deoxyribonucleic acid (DNA) [6,7]. Although a broad variety of non-covalent interactions are recognised, of which hydrogen bonding and $\pi \cdots \pi$ interaction are likely the most well known and widely used in molecular chemistry and biology, and particularly in crystal engineering [8-26], still new specific non-covalent interactions have been discovered and deserved much attention. $\sigma$-Hole interactions, a specific family of non-covalent interactions, formed between a negative site (anion or lone pair of a Lewis acid) and a covalently bonded atom [27], are in the limelight of supramolecular chemistry [25-29]. These $\sigma$-hole interactions, denoted as «spodium bonds», which are attractive interactions between electron rich atoms and any element of group 12, were recently postulated and legalized $[25,30]$. Thus, this newly discovered type of non-covalent interactions, along with the already known and widely utilized non-covalent interactions such as coinage bonding, triel bonding, tetrel bonding, pnictogen bonding, chalcogen bonding, halogen bonding and nobel gas bonding $[25,30]$, is of importance and value in the field of coordination chemistry, particularly for the formation of coordination polymers (CPs).

CPs, being constructed from metal ions (nodes) and bridging ligands (linkers), yield infinite arrays of different dimensionality [31-36]. As such, coordination bonds are a primary driver for the formation of the network in CPs, but non-covalent interactions could have a structureguiding role. In this regard, the use of a pronounced soft metal center like $\mathrm{Hg}(\mathrm{II})$ ion for the formation of CPs is of particular interest since it might be involved in spodium bonding, thus, yielding extended structures with potential new properties.

With all this in mind and in continuation of our ongoing interest in the coordination chemistry of carbohydrazone derivatives as well in study the role of non-covalent interactions in the formation of extended structures [37-48], we have directed our attention to the $N^{\prime}$-(1-(pyridin2-yl)ethylidene)nicotinohydrazide molecule (HL), which is a pincertype ligand. HL belongs to a family of hydrazide derivatives, namely $N$ '-(pyridin-2/3/4-ylmethylene)picolino/nicotino/iso-

nicotinohydrazide (HA), $N^{\prime}$-(1-(pyridin-2/3/4-yl)ethylidene)picolino/ nicotino/isonicotinohydrazide (HB) and $N^{\prime}$-(phenyl(pyridin-2/3/4-yl) methylene)picolino/nicotino/isonicotinohydrazide (HC) (Chart 1). A detailed search in the Crystal Structure Database [49] retrieved 20 crystal structures of HA [38,44,50-55], 7 of $\mathbf{H B}[51,54,56,57]$ and 7 of HC $[54,56,57]$ with $\mathrm{Hg}(\mathrm{II})$, of which, the great majority corresponds to coordination compounds with $\mathrm{HgX}_{2}(\mathrm{X}=\mathrm{Cl}, \mathrm{Br}, \mathrm{I})$. Among these crystal structures, three include $\mathrm{Hg}(\mathrm{SCN})_{2}$ with the $N^{\prime}$-(pyridin-3-ylmethylene) nicotinohydrazide $\left(\mathbf{H A}^{\prime \prime}\right),\left[\mathbf{H g}\left(\mathbf{H A}^{\prime \prime}\right)(\mathbf{S C N})_{2}\right]_{2}$ [44], $N^{\prime}$-(1-(pyridin-2-yl) ethylidene)isonicotinohydrazide $\left(\mathbf{H B}^{\prime}\right),\left[\mathbf{H g}\left(\mathbf{H B}^{\prime}\right)(\mathbf{S C N})_{2}\right]$ [57], and $N^{\prime}-$ (phenyl(pyridin-2-yl)methylene)isonicotinohydrazide ligand $\left(\mathbf{H C}^{\prime}\right)$, $\left[\mathbf{H g}\left(\mathbf{H C}^{\prime}\right)(\mathbf{S C N})_{2}\right]$ [57]. Notably, the organic $\mathbf{H B}^{\prime}$ ligand in $\left[\mathbf{H g}\left(\mathbf{H B}^{\prime}\right)\right.$ $(\mathrm{SCN})_{2}$ ] is coordinated in the "parent" zwitterion form, namely 1(pyridin-2-yl)ethylidenepyridin-1-ium-4-carbohydrazonate, with the $N$ protonated 4-pyridyl fragment [57].

Therefore, the coordination chemistry of $\mathrm{Hg}$ (II) with hydrazide derivatives $\mathbf{H A}, \mathrm{HB}$ and $\mathrm{HC}$ is of interest in order to clarify the interactions occurring in the solid state of these compounds. In this work we have shed light on the structure-driven non-covalent interactions, including spodium bonding, of a new $\mathrm{Hg}$ (II) coordination compound, [ $\mathrm{Hg}(\mathrm{HL})$ $(\mathrm{SCN})_{2}$ ], which was readily obtained by self-assembly of $\mathrm{Hg}(\mathrm{SCN})_{2}$ with HL. The spodium bonding interactions and secondary $\mathrm{C}-\mathrm{H} \cdots \mathrm{O}$ hydrogen bonds have been evaluated energetically by using DFT calculations and characterized by means of the QTAIM and NCIplot index computational<smiles>O=C(N/N=C/c1ccnnn1)c1ccnnn1</smiles><smiles>C/C(=N\NC(=O)c1ccnnn1)c1ccnnn1</smiles><smiles>C/C=C(\c1ccccc1)c1ccnnn1</smiles>

Chart 1. Diagrams of the $N^{\prime}$-(pyridin-2/3/4-ylmethylene)picolino/nicotino/ isonicotionhydrazide (HA), $N^{\prime}$-(1-(pyridin-2/3/4-yl)ethylidene)picolino/nicotino/isonicotionhydrazide (HB) and $N$ '-(phenyl(pyridin-2/3/4-yl)methylene) picolino/nicotino/isonicotionhydrazide (HC).

tools.

\section{Experimental and theoretical methods}

\subsection{Physical measurements}

Infrared spectra ( $\mathrm{KBr}$ pellets) were recorded with a Bruker spectrometer in the range $400-4000 \mathrm{~cm}^{-1}$. Thermogravimetric (TG) analysis was performed by using a Perkin Elmer Pyris Diamond TG/DTA instrument in a dynamic air atmosphere $\left(100 \mathrm{~mL} \cdot \mathrm{min}^{-1}\right)$ from 25 to $950{ }^{\circ} \mathrm{C}$ with a $10^{\circ} \mathrm{C} \mathrm{min}^{-1}$ heating rate. Microanalysis was performed using a Thermo Flash 2000 CHNS analyzer.

\subsection{Synthesis}

The synthesis was carried out using a branched tube method [41]. A mixture of $\mathrm{Hg}(\mathrm{SCN})_{2}(0.158 \mathrm{~g}, 0.5 \mathrm{mmol})$ and $\mathrm{HL}(0.120 \mathrm{~g}, 0.5 \mathrm{mmol})$ was placed in the main arm of the branched tube, and methanol $(25 \mathrm{~mL})$ was carefully added to fill the arms. The tube was sealed and immersed in an oil bath at $60{ }^{\circ} \mathrm{C}$, while the branched arm was kept at ambient temperature. After 7 days, yellow plate-like X-ray suitable crystals were formed in the cooler arm. Crystals were isolated by filtration, washed with acetone and ether, and dried in air. Yield: $0.223 \mathrm{~g}$ (80\%). Anal. Calc. for $\mathrm{C}_{15} \mathrm{H}_{12} \mathrm{HgN}_{6} \mathrm{OS}_{2}$ (557.01): C 32.35, H 2.17 and N 15.09\%; found: C 32.20 , H 2.09 and N 15.16\%. 


\subsection{Single-crystal $X$-ray diffraction}

Cell refinement, indexing, and scaling of the data sets were carried out using the Nonius Collect [58] and EvalCCD programs [59]. The structure was solved by direct methods (SIR92) [60] and subsequent Fourier analyses [61] and refined by the full-matrix least-squares method based on $F^{2}$ with all observed reflections [61]. Hydrogen atoms were placed at calculated positions and included in final cycles of refinement.

Crystal data: $\mathrm{C}_{15} \mathrm{H}_{12} \mathrm{HgN}_{6} \mathrm{OS}_{2}, M_{\mathrm{r}}=557.02 \mathrm{~g} \mathrm{~mol}^{-1}$, triclinic, space group $P \overline{1}, a=8.8425(8), b=9.0529(6), c=13.0804(8) \AA$, $\alpha=72.157$ (5), $\beta=89.974(5), \gamma=62.26(1)^{\circ}, V=869.52(15) \AA^{3}, Z=2, \rho=2.128 \mathrm{~g}$ $\mathrm{cm}^{-3}, \mu(\mathrm{Mo}-\mathrm{K} \alpha)=9.107 \mathrm{~mm}^{-1}$, reflections: 37,822 collected, 7600 unique, $R_{\text {int }}=0.030, R_{1}$ (all) $=0.0443$, $\mathrm{w}_{2}$ (all) $=0.1044, S=1.158$.

CCDC 2033929 contains the supplementary crystallographic data. These data can be obtained free of charge via http://www.ccdc.cam.ac. uk/conts/retrieving.html, or from the Cambridge Crystallographic Data Centre, 12 Union Road, Cambridge CB2 1EZ, UK; fax: $(+44)$ 1223-336033; or e-mail: deposit@ccdc.cam.ac.uk.

\subsection{Theoretical methods}

The non-covalent interactions were analyzed energetically using Gaussian-16 [62] at the PBE0-D3/def2-TZVP level of theory. The binding energies have been corrected using the Boys and Bernardi counterpoise method [63]. The Grimme's D3 dispersion correction has been also used in the calculations [64]. To evaluate the interactions in the solid state, the crystallographic coordinates were used and only the position of the hydrogen atoms has been optimized. This methodology and level of theory has been previously used to analyze non-covalent interactions in the solid state $[65,66]$. The interaction energies were estimated by calculating the difference between the energies of the isolated monomers and the ones of their assembly. The QTAIM analysis [67] and NCIplot index [68] have been computed at the same level of theory by means of the AIMAll program [69].

\section{Results and discussion}

A one-pot reaction of a mixture of $\mathrm{Hg}(\mathrm{SCN})_{2}$ and a bis-pyridyl organic ligand $\mathrm{HL}$ in a branched tube apparatus in $\mathrm{MeOH}$ at $60{ }^{\circ} \mathrm{C}$ leads to a discrete heteroleptic coordination compound [Hg(HL)(SCN $\left.)_{2}\right]$ (Scheme 1). The complex was isolated as yellow air- and moisture stable plate-like crystals in good yield, testifying the reported composition as the main final product, which was characterized by elemental analysis, IR spectroscopy and single-crystal X-ray diffraction. Its thermal behaviour was also studied by the means of TG/DSC analysis.

The FTIR spectrum of the obtained complex exhibits an intense band centered at $2115 \mathrm{~cm}^{-1}$ corresponding to the $\mathrm{CN}$ stretch of the thyiocyanate anions (Fig. 1). This band is in the region characteristic for the Scoordinated $\mathrm{SCN}^{-}$ions [70]. In addition, the spectrum contains an intense band at $1653 \mathrm{~cm}^{-1}$, characteristic for the $\mathrm{C}=\mathrm{O}$ group, and a broad band after about $3250 \mathrm{~cm}^{-1}$, corresponding to the $\mathrm{NH}$ vibration (Fig. 1). The $\mathrm{C}=\mathrm{O}$ and $\mathrm{NH}$ groups in the FTIR specrum of the parent ligand HL were observed as an intense band at $1660 \mathrm{~cm}^{-1}$ and a broad band at about $3205 \mathrm{~cm}^{-1}$ (Fig. 1).

According to the TG/DSC analysis, complex $\left[\mathrm{Hg}(\mathrm{HL})(\mathrm{SCN})_{2}\right]$ melts at $187^{\circ} \mathrm{C}$ followed by decomposition in three gradual steps (Fig. 2). The first step, most likely, corresponds to the loss of HL, and the next decomposition steps are due to the decomposition of mercury thiocyanate.

Compound $\left[\mathrm{Hg}(\mathrm{HL})(\mathrm{SCN})_{2}\right]$ crystallizes in triclinic space group $P \overline{1}$ and its asymmetric unit consists of one complex molecule [ $\mathrm{Hg}(\mathrm{HL})$ $\left.(\mathrm{SCN})_{2}\right]$ (Fig. 3). The metal is coordinated by the tridentate $\mathrm{N}, \mathrm{N}, \mathrm{O}$ donors of the pincer type chelating $\mathrm{HL}$ and by the sulfur donors of two thiocyanate anions. The Hg-S bond distances are of 2.4234(16) and<smiles>C/C(=N\NC(=O)c1cccnc1)c1ccccn1</smiles>

HL<smiles></smiles>

Scheme 1. Synthesis of $\left[\mathrm{Hg}(\mathrm{HL})(\mathrm{SCN})_{2}\right]$.

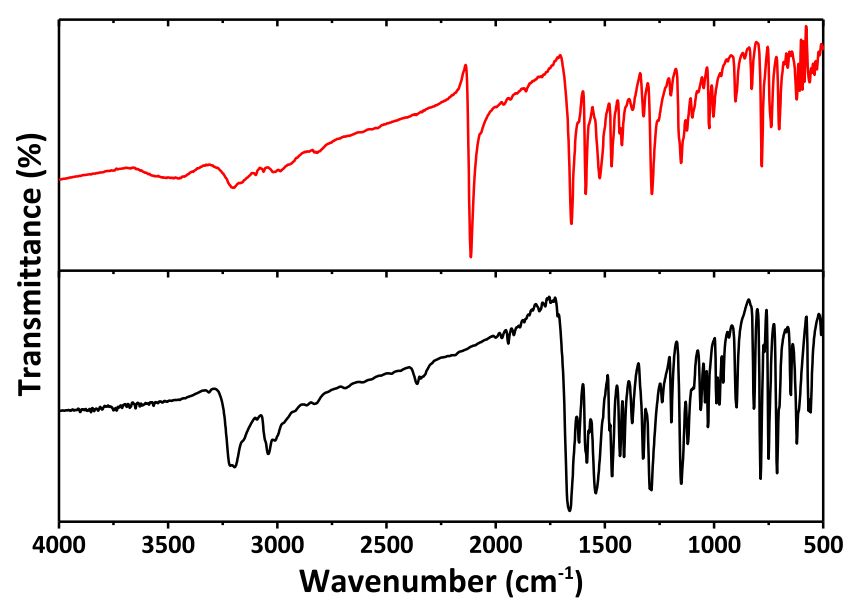

Fig. 1. FTIR spectra of $\mathrm{HL}$ (black) and $\left[\mathrm{Hg}(\mathrm{HL})(\mathrm{SCN})_{2}\right]$ (red).

2.4100(17) $\AA$, while the $\mathrm{Hg}-\mathrm{N}$ and $\mathrm{Hg}-\mathrm{O}$ bond lengths are remarkably longer in the range 2.574(3)-2.649(3) $\AA$, with the following trend $\mathrm{Hg}-\mathrm{N}_{2-\mathrm{Py}}<\mathrm{Hg}-\mathrm{N}(\mathrm{N})<\mathrm{Hg}-\mathrm{O}$ (Table 1 ). Thus, the coordination sphere of the metal ion forms a pentacoordinated geometry, which is best described as being about $64 \%$ along the pathway of distortion from the ideal square pyramidal toward trigonal bipyramidal structure as evidenced from the so-called $\tau_{5}$-descriptor (Table 1) [71,72]. The C-S and $\mathrm{C}-\mathrm{N}$ bond lengths within the $\mathrm{SCN}^{-}$anions are pairwise very similar and typical for the single and triple bonds, respectively (Table 1). Notably, both thiocyanate ligands are almost linear with an average $\mathrm{S}-\mathrm{C}-\mathrm{N}$ bond 


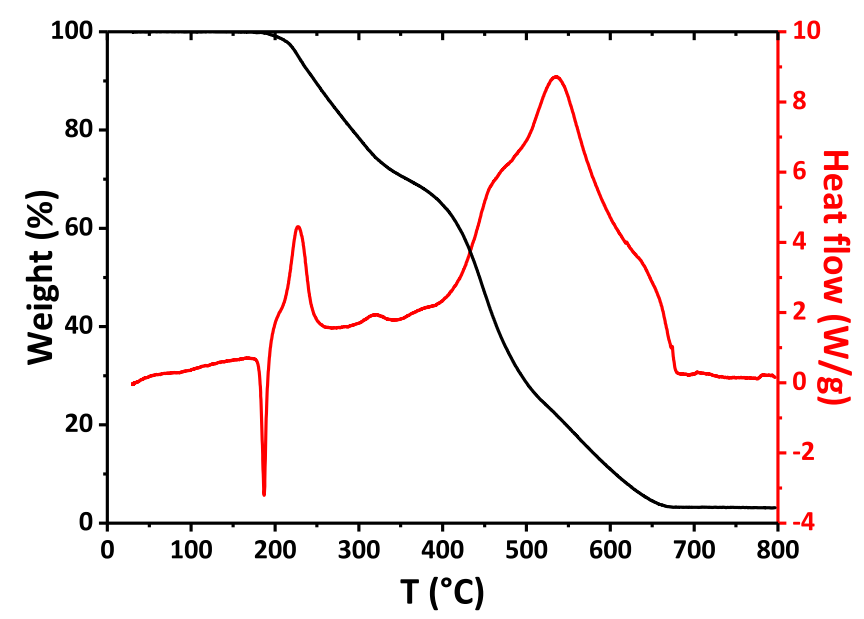

Fig. 2. Simultaneous TG/DSC analyses of $\left[\mathrm{Hg}(\mathrm{HL})(\mathrm{SCN})_{2}\right]$ performed in a dynamic air atmosphere.

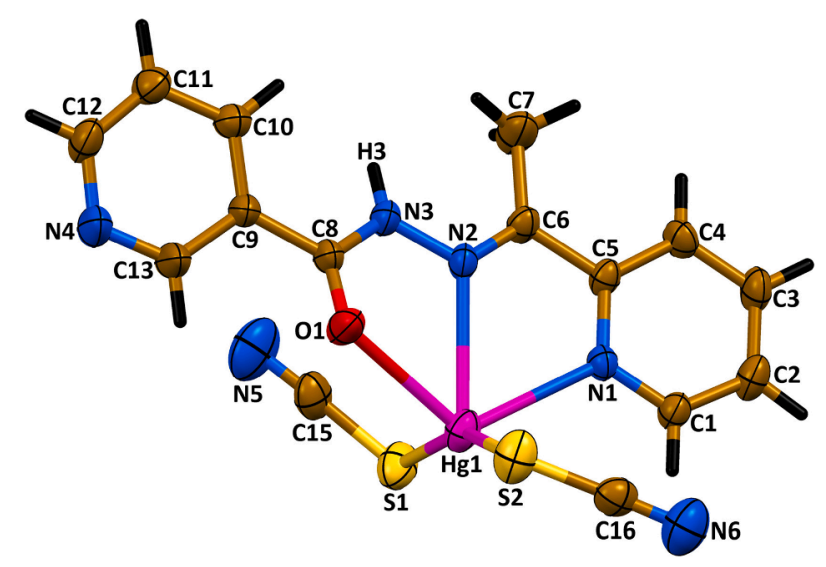

Fig. 3. Molecular structure of $\left[\mathrm{Hg}(\mathrm{HL})(\mathrm{SCN})_{2}\right]$.

angle of about $176.6^{\circ}$, and they exhibit an almost orthogonal coordination mode as evidenced from the corresponding $\mathrm{Hg}-\mathrm{S}-\mathrm{C}$ bond angles of about $100^{\circ}$ (Table 1 ). The organic ligand $\mathrm{HL}$ is flattened as supported by the dihedral angles between the least-square planes formed by the HgNCCN and HgNNCO five-membered chelate rings, and between the 2Py and 3-Py rings (Table 1). However, the HgNNCO chelate ring is remarkably distorted from planarity (Table 1 ) due to the displacement of the carbonyl oxygen atom.

The most striking finding in the crystal structure of $\left[\mathrm{Hg}(\mathrm{HL})(\mathrm{SCN})_{2}\right]$ is the formation of two types of $\mathrm{Hg} \cdots \mathrm{N}$ spodium bonds (Fig. 4, Table 1 ). These bonds are formed with the 3-Py nitrogen atom of a symmetry related molecule in a centrosymmetric fashion, where the metals are separated by $8.334(1) \AA$, and with the nitrogen atom of one thiocyanate ligand of another symmetry related molecule, yielding an eightmembered $\left[\mathrm{Hg}_{2}(\mathrm{SCN})_{2}\right]^{2+}$ structural motif (Fig. 5). This metallocycle is in a chair conformation, whereby the two metal cations deviate by about $1.52 \AA$ from the least-square plane through the two thiocyanate anions, and are separated by $6.337(1) \AA$. As a result of the $\mathrm{Hg} \cdots \mathrm{N}$ spodium bonds, firstly, the coordination environment of the metal cation can be described as a capped trigonal prism close to pentagonal bipyramid with the sulfur atoms at the apices (CShM parameters of 4.000 and 4.185, respectively) [73]; and, secondly, a 1D zig-zag-like polymeric chain is formed along the [1 01] direction, which is further reinforced by bilateral $\mathrm{C}-\mathrm{H} \cdots \mathrm{O}$ hydrogen bonds (Table 2 ). These chains are interlinked through the bilateral $\mathrm{N}-\mathrm{H} \cdots \mathrm{N}$ hydrogen bonds (Fig. 4, Table 2), formed between the amide hydrogen atoms and the nitrogen atoms of the remaining thiocyanate anions, and additionaly glued by $\pi \cdots \pi$
Table 1

Selected bond lengths $(\AA)$ and angles $\left(^{\circ}\right)$ in the structure of $[\mathrm{Hg}(\mathrm{HL})(\mathrm{SCN})$

\begin{tabular}{|c|c|c|c|}
\hline \multicolumn{4}{|l|}{ Bond lengths ${ }^{\mathrm{a}}$} \\
\hline Hg1-N1 & $2.574(3)$ & $\mathrm{C} 8-\mathrm{O} 1$ & $1.233(5)$ \\
\hline $\mathrm{Hg} 1-\mathrm{N} 2$ & $2.611(3)$ & N2-N3 & $1.373(4)$ \\
\hline Hg1-O1 & $2.649(3)$ & C15-N5 & $1.140(8)$ \\
\hline $\mathrm{Hg} 1-\mathrm{S} 1$ & $2.4234(16)$ & C16-N6 & $1.145(8)$ \\
\hline $\mathrm{Hg} 1-\mathrm{S} 2$ & $2.4100(17)$ & C15-S1 & $1.664(5)$ \\
\hline $\mathrm{Hg} 1 \cdots \mathrm{N} 4^{\# 1}$ & $2.936(5)$ & C16-S2 & $1.653(5)$ \\
\hline $\mathrm{Hg} 1 \cdots \mathrm{N}^{\# 2}$ & $3.146(6)$ & & \\
\hline \multicolumn{4}{|l|}{ Bond angles $^{\mathrm{a}}$} \\
\hline N1-Hg1-N2 & $61.82(9)$ & O1-Hg1-S2 & $84.63(10)$ \\
\hline N1-Hg1-O1 & $119.20(9)$ & $\mathrm{O} 1-\mathrm{Hg} 1 \cdots \mathrm{N} 4^{\# 1}$ & $71.07(12)$ \\
\hline N1-Hg1-S1 & $93.61(9)$ & $\mathrm{O} 1-\mathrm{Hg} 1 \cdots \mathrm{N} 6^{\# 2}$ & $150.31(14)$ \\
\hline N1-Hg1-S2 & $99.69(9)$ & $\mathrm{S} 1-\mathrm{Hg} 1-\mathrm{S} 2$ & $157.45(5)$ \\
\hline $\mathrm{N} 1-\mathrm{Hg} 1 \cdots \mathrm{N} 4^{\# 1}$ & $169.58(11)$ & $\mathrm{S} 1-\mathrm{Hg} 1 \cdots \mathrm{N} 4^{\# 1}$ & $84.83(13)$ \\
\hline $\mathrm{N} 1-\mathrm{Hg} 1 \cdots \mathrm{N} 6^{\# 2}$ & $90.09(14)$ & $\mathrm{S} 1-\mathrm{Hg} 1 \cdots \mathrm{N} 6^{\# 2}$ & $76.09(15)$ \\
\hline N2-Hg1-O1 & $59.84(10)$ & $\mathrm{S} 2-\mathrm{Hg} 1 \cdots \mathrm{N} 4^{\# 1}$ & $78.80(13)$ \\
\hline N2-Hg1-S1 & $92.84(9)$ & $\mathrm{S} 2-\mathrm{Hg} 1 \cdots \mathrm{N} 6^{\# 2}$ & $85.71(14)$ \\
\hline N2-Hg1-S2 & $109.48(9)$ & Hg1-S1-C15 & $100.54(19)$ \\
\hline $\mathrm{N} 2-\mathrm{Hg} 1 \cdots \mathrm{N} 4^{\# 1}$ & $128.50(12)$ & Hg1-S2-C16 & $103.4(2)$ \\
\hline $\mathrm{N} 2-\mathrm{Hg} 1 \cdots \mathrm{N} 6^{\# 2}$ & $149.41(14)$ & S1-C15-N5 & $176.3(6)$ \\
\hline O1-Hg1-S1 & $104.68(11)$ & S2-C16-N6 & $176.8(6)$ \\
\hline \multicolumn{4}{|l|}{ Dihedral angles ${ }^{\mathrm{b}}$} \\
\hline HgNCCN $\cdots$ HgNNCO & $14.32(18)$ & HgNNCO $\cdots 2-\mathrm{Py}$ & $18.1(2)$ \\
\hline HgNCCN $\cdots 2-\mathrm{Py}$ & $4.0(2)$ & HgNNCO $\cdots 3$-Py & $20.3(2)$ \\
\hline HgNCCN ‥3-Py & $7.3(2)$ & 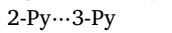 & $6.6(3)$ \\
\hline
\end{tabular}

${ }^{a}$ Symmetry transformations used to generate equivalent atoms: \#1 $1-x, 1-$ $y, 1-z ; \# 22-x,-y, 2-z$.

b Dihedral angles between the least-square planes formed by the indicated rings within the ligand $\mathrm{HL}$.

interactions between the 2-Py rings (Fig. 4, Table 3). As a result, a 2D supramolecular polymeric layer is formed parallel to the crystallographic (011) plane (Fig. 4). Considering all the $\mathrm{Hg} \cdots \mathrm{N}$ spodium and $\mathrm{N}-\mathrm{H} \cdots \mathrm{N}$ hydrogen bonds, this 2D layer was simplified using the ToposPro software [74], resulting in a binodal 3,4-connected hcb topology defined by the point symbol of $\left(4^{2} \cdot 6^{3} \cdot 8\right)\left(4^{2} \cdot 6\right)$ (Fig. 4). Furthermore, the resulting 2D layers are interlinked through $\pi \cdots \pi$ interactions, formed between the five-membered HgNCCN chelate metallocycles and 3-Py rings, and between 2-Py and 3-Py rings (Table 3), giving rise to a 3D architecture.

A comparison of the crystal structure of $\left[\mathrm{Hg}(\mathrm{HL})(\mathrm{SCN})_{2}\right]$ with its closest analogues $\left[\mathrm{Hg}\left(\mathrm{HA}^{\prime \prime}\right)(\mathbf{S C N})_{2}\right]_{2}[44],\left[\mathbf{H g}\left(\mathrm{HB}^{\prime}\right)(\mathbf{S C N})_{2}\right][57]$ and $\left[\mathrm{Hg}\left(\mathrm{HC}^{\prime}\right)(\mathbf{S C N})_{2}\right]$ [57] revealed that the supramolecular aggregation of $\left[\mathrm{Hg}\left(\mathrm{HA}^{\prime \prime}\right)(\mathrm{SCN})_{2}\right]_{2}$ and $\left[\mathrm{Hg}\left(\mathrm{HC}^{\prime}\right)(\mathrm{SCN})_{2}\right]$ is also constructed by $\mathrm{Hg} \cdots \mathrm{N}$ spodium bonds but exclusively formed with the nitrogen atoms of the terminal thiocyanate anions, yielding to different topologies, while no spodium bonds were observed in the structure of $\left[\mathrm{Hg}\left(\mathrm{HB}^{\prime}\right)(\mathrm{SCN})_{2}\right]$. Thus, the structure of the parent organic ligand plays a pivotal role in the supramolecular aggreagation of $\mathbf{H A}, \mathbf{H B}$ and $\mathbf{H C}$ with $\mathrm{Hg}(\mathrm{SCN})_{2}$.

The crystal packing of $\left[\mathrm{Hg}(\mathrm{HL})(\mathrm{SCN})_{2}\right]$ was further studied by a Hirshfeld surface analysis [75], and the obtained set of corresponding 2D fingerprint plots [76] was generated using CrystalExplorer 17 [77]. The enrichment ratios $(E)$ [78] of the intermolecular contacts were also calculated to estimate the propensity of two chemical species to be in contact. It was found that the Hirshfeld surface of $\left[\mathrm{Hg}(\mathrm{HL})(\mathrm{SCN})_{2}\right]$, calculated over $d_{\text {norm }}$, contains nine bright and faint red spots, corresponding to donor and acceptor atoms of the mutual $\mathrm{H} \cdots \mathrm{H}, \mathrm{H} \cdots \mathrm{C}, \mathrm{H} \cdots \mathrm{N}$, $\mathrm{H} \cdots \mathrm{O}, \mathrm{C} \cdots \mathrm{C}$ and $\mathrm{Hg} \cdots \mathrm{N}$ intermolecular interactions (Fig. 6). The donor and acceptor atoms of these interactions can be evidenced as blue and red regions around the participating atoms on the Hirshfeld surface mapped over shape index (Fig. 6). Moreover, an expanded flat region is clearly observed over one side of the molecule on the Hirshfeld surface mapped over curvedness, testifying reasonable $\pi \cdots \pi$ interactions (Fig. 6).

It was also established that two main groups of intermolecular contacts occupy the total Hirshfeld surface of $\left[\mathrm{Hg}(\mathrm{HL})(\mathrm{SCN})_{2}\right]$. The first and the dominant one occupies about $75 \%$ of the molecular surface and 

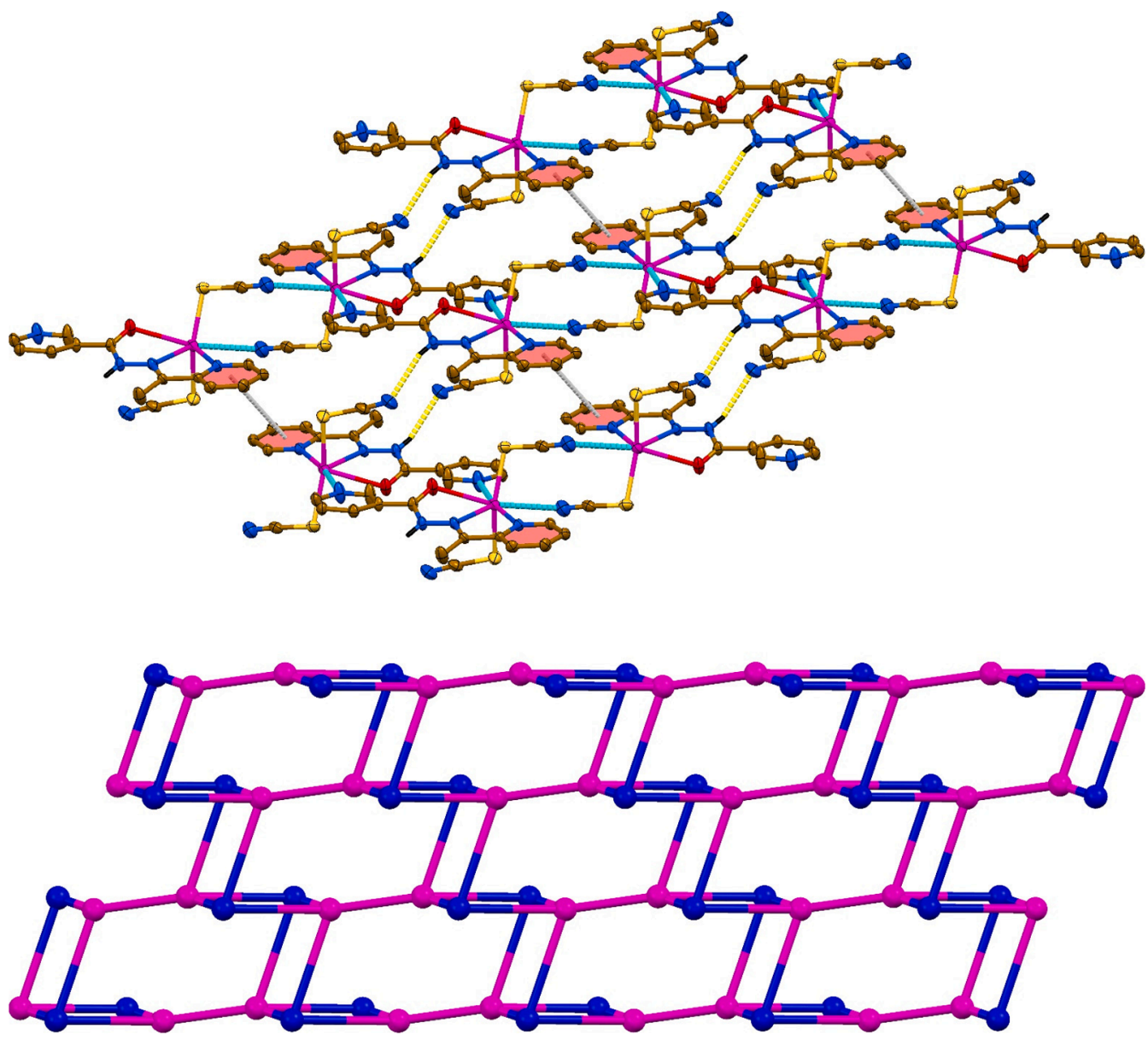

Fig. 4. (top) The 2D supramolecular polymeric layer in the crystal structure of $\left[\mathrm{Hg}(\mathrm{HL})(\mathrm{SCN})_{2}\right]$, built by the $\mathrm{Hg} \cdots \mathrm{N}$ spodium bonds, $\mathrm{N}-\mathrm{H} \cdots \mathrm{N}$ hydrogen bonds and $\pi \cdots \pi$ interactions (H-atoms, except those inolved in $\mathrm{N}-\mathrm{H} \cdots \mathrm{N}$ hydrogen bonds, were omitted for clarity). Color codes: $\mathrm{H}=$ black, $\mathrm{C}=$ gold, $\mathrm{N}=$ blue, $\mathrm{O}=$ red, $\mathrm{S}=$ yellow, $\mathrm{Hg}$ $=$ magenta; $\mathrm{Hg} \cdots \mathrm{N}$ spodium bond $=$ dashed cyan line, $\mathrm{N}-\mathrm{H} \cdots \mathrm{N}$ hydrogen bond $=$ dashed yellow line, $\pi \cdots \pi$ interaction $=$ dashed grey line. (bottom) A simplified network of $\left[\mathrm{Hg}(\mathrm{HL})(\mathrm{SCN})_{2}\right]$, considering the $\mathrm{Hg} \cdots \mathrm{N}$ spodium and $\mathrm{N}-\mathrm{H} \cdots \mathrm{N}$ hydrogen bonds, with the binodal 3,4-connected hcb topology defined by the point symbol of $\left(4^{2} \cdot 6^{3} \cdot 8\right)$ $\left(4^{2} \cdot 6\right)$. Color code: $\mathrm{Hg}=$ magenta, $\mathrm{HL}=$ blue. (For interpretation of the references to colour in this figure legend, the reader is referred to the web version of this article.)

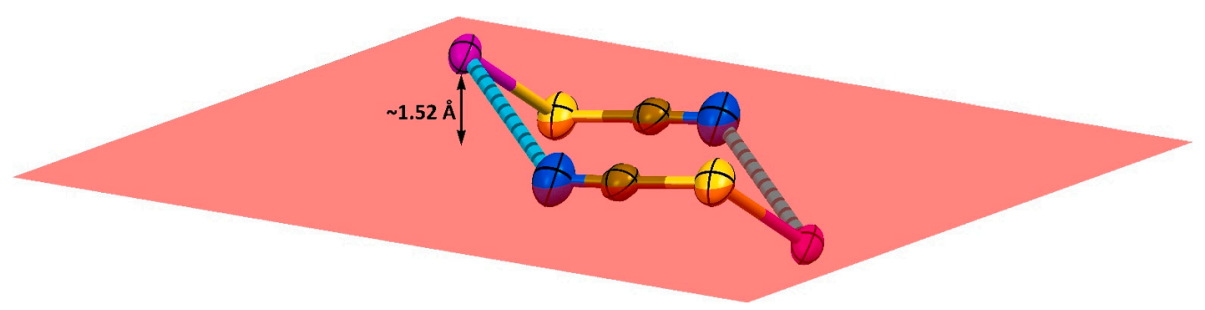

Fig. 5. The eight-membered $\left[\mathrm{Hg}_{2}(\mathrm{SCN})_{2}\right]^{2+}$ motif, adopting a chair conformation, formed by means of two $\mathrm{Hg} \cdots \mathrm{N}$ spodium bonds in the crystal structure of $[\mathrm{Hg}$ $\left.(\mathrm{HL})(\mathrm{SCN})_{2}\right]$.

Table 2

Hydrogen bond lengths $(\AA)$ and angles $\left({ }^{\circ}\right)$ for $\left[\mathrm{Hg}(\mathrm{HL})(\mathrm{SCN})_{2}\right]$. $^{\text {a }}$

\begin{tabular}{lllll}
\hline $\mathrm{D}-\mathrm{X} \cdots \mathrm{A}$ & $d(\mathrm{D}-\mathrm{X})$ & $d(\mathrm{X} \cdots \mathrm{A})$ & $d(\mathrm{D} \cdots \mathrm{A})$ & $\angle(\mathrm{DXA})$ \\
\hline $\mathrm{N} 3-\mathrm{H} 3 \cdots \mathrm{N5}^{\# 1}$ & 0.86 & 2.32 & $3.083(9)$ & 147 \\
$\mathrm{C} 13-\mathrm{H} 13 \cdots \mathrm{O} 1^{\# 2}$ & 0.93 & 2.47 & $3.145(7)$ & 130 \\
\hline
\end{tabular}

a Symmetry transformations used to generate equivalent atoms: \#1 $1-x,-y$, $1-z ; \# 21-x, 1-y, 1-z$.

consists of the $\mathrm{H} \cdots \mathrm{H}, \mathrm{H} \cdots \mathrm{C}, \mathrm{H} \cdots \mathrm{N}$ and $\mathrm{H} \cdots \mathrm{S}$ contacts accounting for $15.9-22.3 \%$ (Table 4). The second group of contacts occupies $22 \%$ of the Hirshfeld surface and consists of the $\mathrm{H} \cdots \mathrm{O}, \mathrm{C} \cdots \mathrm{C}, \mathrm{C} \cdots \mathrm{N}, \mathrm{N} \cdots \mathrm{S}$ and $\mathrm{Hg} \cdots \mathrm{N}$ contacts accounting for 2.8-6.3\% (Table 4). Remaining observed contacts, viz. $\mathrm{C} \cdots \mathrm{S}, \mathrm{N} \cdots \mathrm{N}, \mathrm{N} \cdots \mathrm{O}$ and $\mathrm{Hg} \cdots \mathrm{H}$, are very negligible and occupy less than $3 \%$ of the molecular surface (Table 4 ). The shorter $\mathrm{H} \cdots \mathrm{N}$ and $\mathrm{H} \cdots \mathrm{O}$ contacts are shown in the corresponding 2D fingerprint plots at $d_{\mathrm{e}}$ $+d_{\mathrm{i}} \approx 2.2$ and $2.4 \AA$, respectively, and are indicated as a pair of sharp
Table 3

$\pi \cdots \pi$ interaction lengths $(\AA)$ and angles $\left(^{\circ}\right)$ for $\left[\mathrm{Hg}(\mathrm{HL})(\mathrm{SCN})_{2}\right] .^{\text {a,b }}$

\begin{tabular}{|c|c|c|c|c|c|}
\hline $\operatorname{Cg}(I) \cdots \operatorname{Cg}(J)$ & $d[\operatorname{Cg}(I) \cdots \operatorname{Cg}(J)]$ & $\alpha$ & $\beta$ & $\gamma$ & slippage \\
\hline HgNCCN $\cdots 3-\mathrm{Py}^{\# 1}$ & $4.028(3)$ & $7.3(2)$ & 29.2 & 36.1 & 1.965 \\
\hline 3-Py $\cdots \mathrm{HgNCCN}^{\# 1}$ & $4.027(3)$ & $7.3(2)$ & 36.1 & 29.2 & 2.372 \\
\hline $2-\mathrm{Py} \cdots 2-\mathrm{Py}^{\# 2}$ & $3.933(2)$ & $0.0(2)$ & 33.0 & 33.0 & 2.145 \\
\hline $2-\mathrm{Py} \cdots 3-\mathrm{Py}^{\# 1}$ & $3.752(3)$ & $6.6(3)$ & 22.4 & 28.6 & 1.429 \\
\hline $3-\mathrm{Py} \cdots 2-\mathrm{Py}^{\# 1}$ & $3.751(3)$ & $6.6(3)$ & 28.6 & 22.4 & 1.795 \\
\hline
\end{tabular}

${ }^{a} \operatorname{Cg}(I) \cdots \operatorname{Cg}(J)$ : distance between ring centroids; $\alpha$ : dihedral angle between planes $\operatorname{Cg}(I)$ and $\operatorname{Cg}(J) ; \beta$ : angle $\operatorname{Cg}(I) \rightarrow \operatorname{Cg}(J)$ vector and normal to plane $I ; \gamma$ : angle $\mathrm{Cg}(I) \rightarrow \operatorname{Cg}(J)$ vector and normal to plane $J$; slippage: distance between $\mathrm{Cg}$ $(I)$ and perpendicular projection of $\operatorname{Cg}(J)$ on ring $I$.

b Symmetry transformations used to generate equivalent atoms: \#1 $2-x,-y$, $1-z ; \# 22-x,-1-y, 2-z$. 

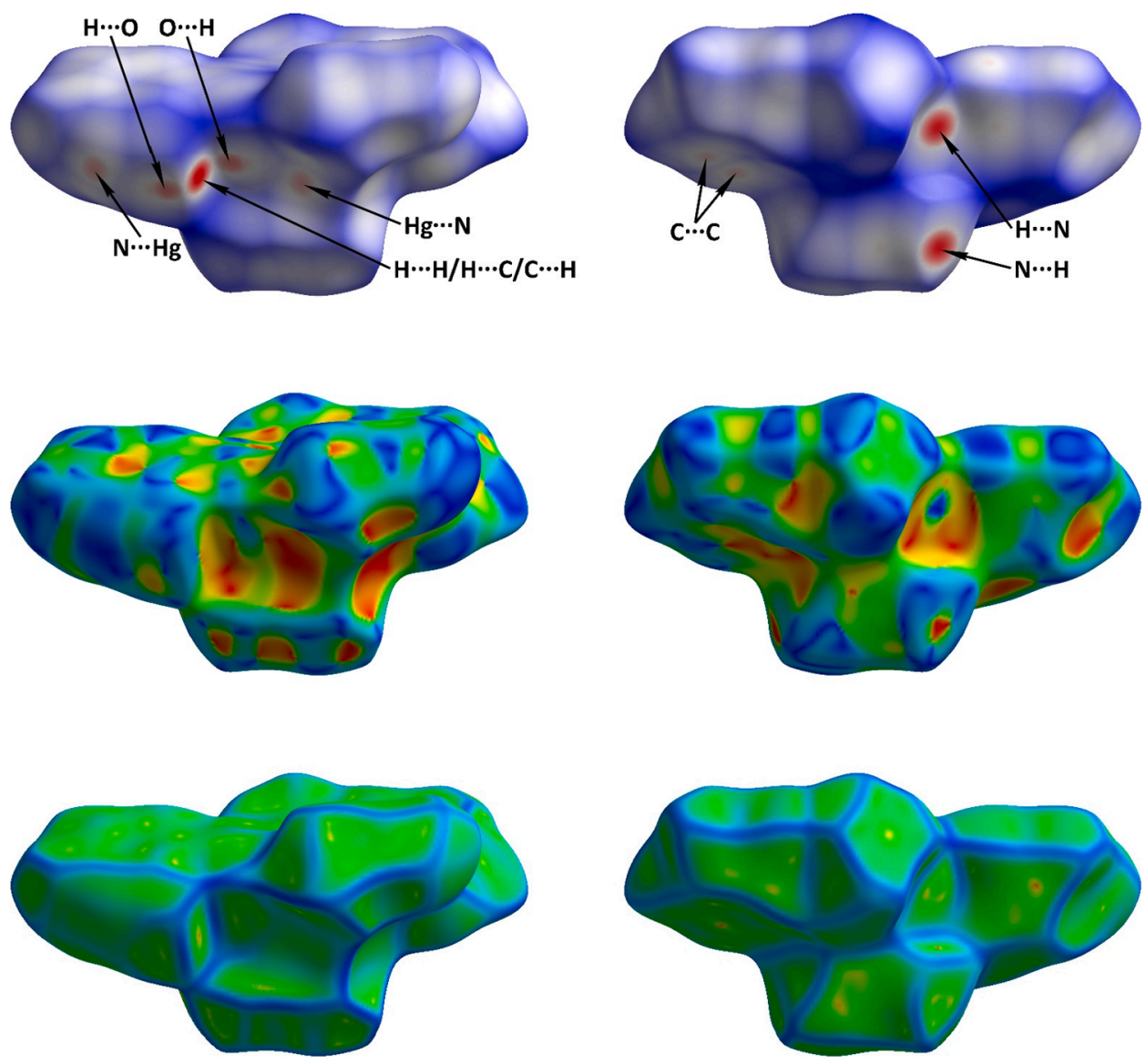

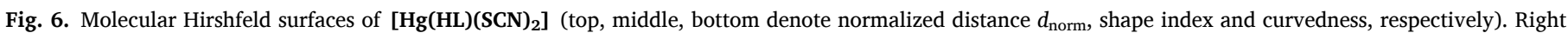
column views are figures $180^{\circ}$ rotated of those in left column.

spikes or horns (Table 4) due to the formation of intermolecular $\mathrm{N}-\mathrm{H} \cdots \mathrm{N}$ and $\mathrm{C}-\mathrm{H} \cdots \mathrm{O}$ hydrogen bonds (Table 2). Furthermore, the $\mathrm{C} \cdots \mathrm{C}$ contacts are shown in the fingerprint plot as the characteristic area on the diagonal at $d_{\mathrm{e}}=d_{\mathrm{i}} \approx 1.7-2.2 \AA$ (Table 4 ) and correspond to $\pi \cdots \pi$ interactions. Notably, the $\mathrm{Hg} \cdots \mathrm{N}$ contacts are also shown in the $2 \mathrm{D}$ fingerprint plot as a pair of sharp spikes with the shorter $d_{\mathrm{e}}+d_{\mathrm{i}} \approx 2.9 \AA$ (Table 4), indicating the formation of $\mathrm{Hg} \cdots \mathrm{N}$ spodium bonds (Table 1 ). The intermolecular $\mathrm{H} \cdots \mathrm{C}, \mathrm{H} \cdots \mathrm{N}, \mathrm{H} \cdots \mathrm{O}, \mathrm{H} \cdots \mathrm{S}$ and $\mathrm{C} \cdots \mathrm{C}$ contacts are highly favoured in the molecular surface $\left[\mathrm{Hg}(\mathrm{HL})(\mathrm{SCN})_{2}\right]$ since the corresponding enrichment ratios $E_{\mathrm{HH} / \mathrm{HN} / \mathrm{HO} / \mathrm{HS}}$ and $E_{\mathrm{CC}}$ are larger than unity (Table 4), while the N...S contacts are less favoured as evidenced from the corresponding $E_{\mathrm{NS}}$ value of 0.87 . Remaining contacts are significantly impoverished as evidenced from the corresponding enrichment ratios (Table 4).

Finally, a DFT theoretical study has been carried out to study the $\mathrm{Hg} \cdots \mathrm{N}$ spodium bonding interactions (Fig. 4) that are responsible for the formation of the 2D supramolecular polymeric layer. As starting point, the molecular electrostatic potential (MEP) surface of $\left[\mathrm{Hg}(\mathrm{HL})(\mathrm{SCN})_{2}\right]$ has been computed (Fig. 7). It shows that the minimum MEP value (most negative) is located at the nitrogen atom of the thiocyanate ligand ( -44 $\mathrm{kcal} / \mathrm{mol})$. The most positive ones at the aromatic hydrogen atoms, $(+31 \mathrm{kcal} / \mathrm{mol})$. The MEP value at the non-coordinated pyridinic nitrogen atom of the ligand $\mathrm{HL}$ is also large and negative $(-31 \mathrm{kcal} / \mathrm{mol})$. The MEP surface also reveals that the electron distribution at the $\mathrm{Hg}$ (II) ion is anisotropic with the existence of a $\sigma$-hole (a local MEP maximum) of $+20 \mathrm{kcal} / \mathrm{mol}$ that is located opposite to the most electronegative oxygen atom (the $\mathrm{Hg}-\mathrm{O}$ bond is the most polarized). The MEP surface analysis confirms the suitability of $\mathrm{Hg}$ (II) for interacting with electron rich atoms, as observed in the solid state of $\left[\mathrm{Hg}(\mathrm{HL})(\mathrm{SCN})_{2}\right]$.

We have also computed two dimers of $\left[\mathrm{Hg}(\mathrm{HL})(\mathrm{SCN})_{2}\right]$ to study the energetic features of both types of spodium bonds present in the solid state (one with SCN ligand as electron donor, DIMER-I, and the other with the nitrogen atom of pyridine as Lewis base, DIMER-II). We have used both the quantum theory of atoms in molecules (QTAIM) and noncovalent interaction plot (NCIPlot) computational tools since it has been recently proved their suitability to characterize spodium bonds efficiently [30]. The distribution of critical points and bond paths of DIMER-I (Fig. 8) reveals the presence of two symmetrically equivalent bond critical points (labelled as red spheres) and bond paths (dashed lines) that interconnect the $\mathrm{Hg}$ (II) ions to the nitrogen atoms of the pyridine rings, thus confirming the existence of the spodium bonds. Moreover, the QTAIM analysis shows that there are two symmetrically equivalent $\mathrm{C}-\mathrm{H} \cdots \mathrm{O}$ hydrogen bonds that further stabilize the assembly (see critical points labelled as "a"). Each hydrogen bond is characterized by a bond critical point and bond path connecting the pyridinic $\mathrm{C}-\mathrm{H}$ bond with the coordinated oxygen atom of HL. Such combination of interactions (two hydrogen bonds and two spodium bonds) justify the large dimerization energy of $-11.5 \mathrm{kcal} / \mathrm{mol}$. The existence of both interactions is also confirmed by the NCIplot surface analysis. The spodium bonds are characterized by blue isosurfaces located between the $\mathrm{Hg}(\mathrm{II})$ - and $\mathrm{N}$-atoms indicating moderately strong interaction. The hydrogen bonds are characterized by green and smaller isosurfaces located between the $\mathrm{H}$ - and $\mathrm{O}$-atoms thus revealing weaker interaction. In the inversion center of the dimer, both the QTAIM and NCIplot methods reveal the existence of a weak $\mathrm{C}-\mathrm{H} \cdots \mathrm{H}-\mathrm{C}$ interaction (see critical point labelled as " $b$ ").

In the other dimer DIMER-II the spodium bonds are characterized by the corresponding bond critical points connecting the $\mathrm{Hg}$ (II) atoms to the nitrogen atoms of the SCN ligand and the NCIplot isosurfaces located between both interacting atoms (Fig. 8). This dimer presents larger 
Table 4

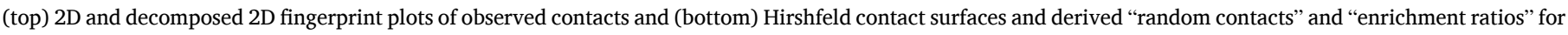
$\left[\mathrm{Hg}(\mathrm{HL})(\mathrm{SCN})_{2}\right]$.

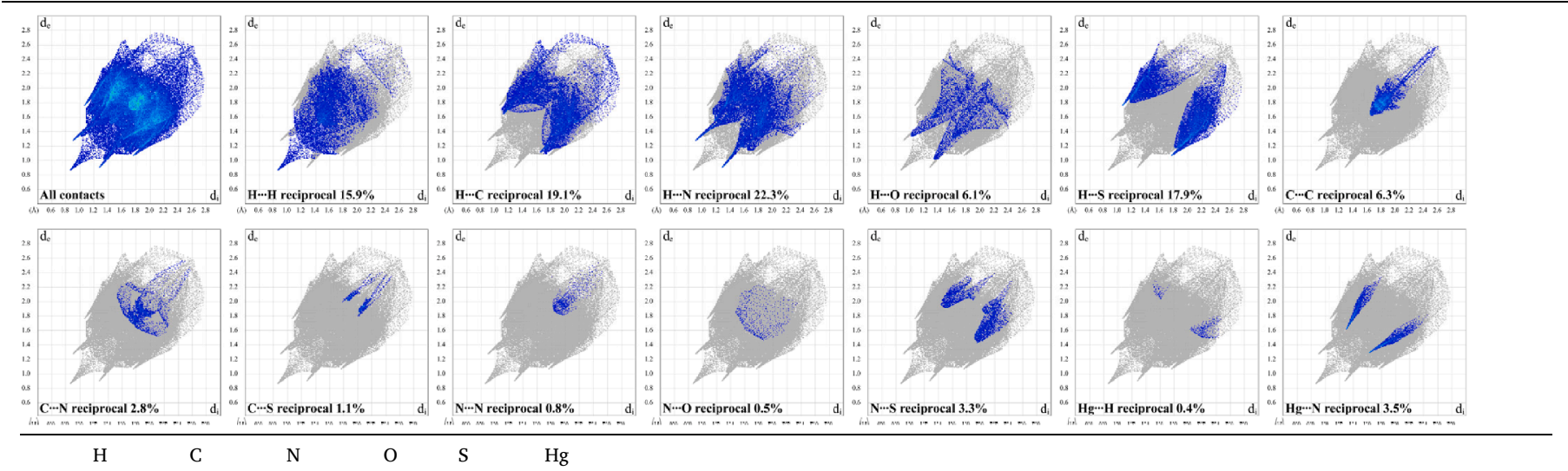

\begin{tabular}{|c|c|c|c|c|c|c|}
\hline \multicolumn{7}{|c|}{ Contacts $(C, \%)^{\mathrm{a}}$} \\
\hline $\mathrm{H}$ & 15.9 & - & - & - & - & - \\
\hline $\mathrm{C}$ & 19.1 & 6.3 & - & - & - & - \\
\hline $\mathrm{N}$ & 22.3 & 2.8 & 0.8 & - & - & - \\
\hline $\mathrm{O}$ & 6.1 & 0.0 & 0.5 & 0.0 & - & - \\
\hline S & 17.9 & 1.1 & 3.3 & 0.0 & 0.0 & - \\
\hline $\mathrm{Hg}$ & 0.4 & 0.0 & 3.5 & 0.0 & 0.0 & 0.0 \\
\hline \multicolumn{7}{|c|}{ Surface $(S, \%)$} \\
\hline & 48.8 & 17.8 & 17.0 & 3.3 & 11.2 & 2.0 \\
\hline \multicolumn{7}{|c|}{ Random contacts $(R, \%)$} \\
\hline $\mathrm{H}$ & 23.8 & - & - & - & - & - \\
\hline $\mathrm{C}$ & 17.4 & 3.2 & - & - & - & - \\
\hline $\mathrm{N}$ & 16.6 & 6.1 & 2.9 & - & - & - \\
\hline $\mathrm{O}$ & 3.2 & 1.2 & 1.1 & 0.1 & - & - \\
\hline S & 10.9 & 4.0 & 3.8 & 0.7 & 1.3 & - \\
\hline $\mathrm{Hg}$ & 2.0 & 0.7 & 0.7 & 0.1 & 0.4 & 0.0 \\
\hline
\end{tabular}

Enrichment $(E)^{\mathrm{b}}$

\begin{tabular}{|c|c|c|c|c|c|c|}
\hline \multicolumn{7}{|c|}{ Enrichment $(E)$} \\
\hline $\mathrm{H}$ & 0.67 & - & - & - & - & - \\
\hline C & 1.10 & 1.97 & - & - & - & - \\
\hline $\mathrm{N}$ & 1.34 & 0.46 & 0.28 & - & - & - \\
\hline $\mathrm{O}$ & 1.91 & 0.00 & 0.45 & - & - & - \\
\hline S & 1.64 & 0.28 & 0.87 & - & & - \\
\hline $\mathrm{Hg}$ & 0.20 & - & - & - & _- & - \\
\hline
\end{tabular}

a Values are obtained from CrystalExplorer 17 [77].

b The "enrichment ratios" were not computed when the "random contacts" were lower than $0.9 \%$, as they are not meaningful [78].

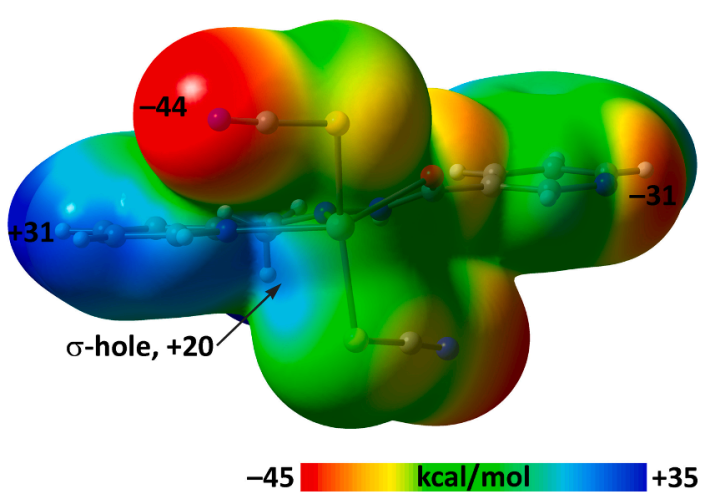

Fig. 7. MEP surface (isosurface 0.001 a.u.) of $\left[\mathrm{Hg}(\mathrm{HL})(\mathrm{SCN})_{2}\right]$ at the PBE0D3/def2-TZVP level of theory.

binding energy ( $-14.1 \mathrm{kcal} / \mathrm{mol})$ because the MEP value at the nitrogen atom of the thiocyanate ligands is more negative than that at the pyridine nitrogen atom. Moreover, in this dimer the nitrogen atom points directly to the $\sigma$-hole (opposite to the $\mathrm{Hg}-\mathrm{O}$ bond). DIMER-II also presents two equivalent $\mathrm{C}-\mathrm{H}$...SCN contacts characterized by a bond critical point (see critical point labelled as "c" in Fig. 8) that connects the hydrogen atom to the central carbon atom of the thiocynanate thus also contributing to the stabilization of the dimer.

In order to evaluate the contribution of the hydrogen bonds and their relative importance in the stabilization of DIMER-I and DIMER-II, we have calculated their individual energy by using the kinetic energy density $\left(V_{r}\right)$ predictor, as proposed in the literature [79]. The $V_{r}$ value at critical point "a" (DIMER-I) is -0.0055 a.u. and, consequently, the hydrogen bond energy using the $E_{\mathrm{HB}}=0.5 \times \mathrm{V}_{\mathrm{r}}$ formula is $-1.73 \mathrm{kcal} /$ mol. Therefore, the total contribution of the hydrogen bonds to DIMER-I is approximately $-3.45 \mathrm{kcal} / \mathrm{mol}$ that is significantly smaller than the spodium bonding energy, which is $-8.04 \mathrm{kcal} / \mathrm{mol}(-4.02 \mathrm{kcal} / \mathrm{mol}$ each spodium bond). The $\mathrm{V}_{\mathrm{r}}$ value at critical point "c" (DIMER-II) is -0.0019 a.u. and, consequently, the energy associated to each $\mathrm{C}-\mathrm{H}$...S SCN contact is only $-0.60 \mathrm{kcal} / \mathrm{mol}$. Therefore, the total contribution of the hydrogen bonds to the formation of DIMER-II is $-1.20 \mathrm{kcal} / \mathrm{mol}$, which is insignificant compared to the spodium bonding energy, which is $-12.9 \mathrm{kcal} /$ $\mathrm{mol}$ ( $-6.5 \mathrm{kcal} / \mathrm{mol}$ each spodium bond). These values agree well with the recently reported energetic features of spodium bonds [80].

\section{Conclusions}

In summary, we have designed and fully characterized a new $\mathrm{Hg}$ (II) coordination compound $\left[\mathrm{Hg}(\mathrm{HL})(\mathrm{SCN})_{2}\right]$, obtained from a mixture of $\mathrm{Hg}(\mathrm{SCN})_{2}$ and bis-pyridyl organic ligand $N^{\prime}$-(1-(pyridin-2-yl)ethylidene) 

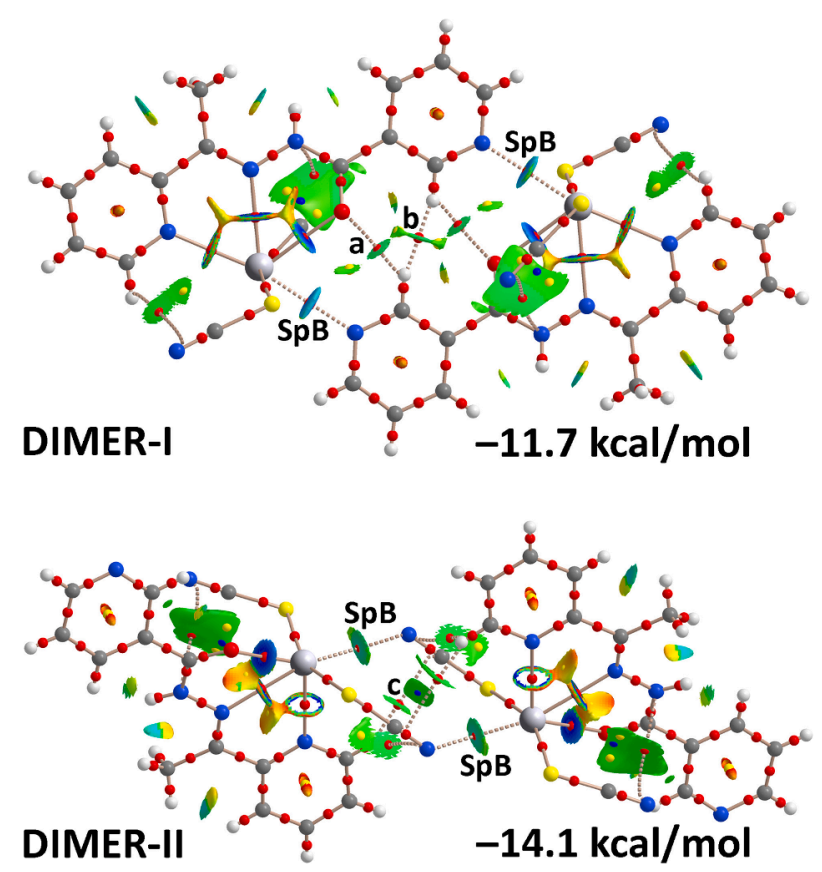

Fig. 8. Combined QTAIM (bond and ring critical points are in red and yellow, respectively) and NCIplot analyses of (top) DIMER-I and (bottom) DIMER-II of $\left[\mathrm{Hg}(\mathrm{HL})(\mathrm{SCN})_{2}\right](\mathrm{SpB}=$ spodium bond). (For interpretation of the references to colour in this figure legend, the reader is referred to the web version of this article.)

nicotinohydrazide (HL) in $\mathrm{MeOH}$. The complex melts at $187^{\circ} \mathrm{C}$ and the decomposition occurs in three gradual steps, of which the first one corresponds to the loss of HL.

The X-ray diffraction analysis shows the metal cation coordinated by the $N, N$, $O$ donors of the pincer type chelating HL and by the sulfur donor of two thiocyanate anions, yielding a pentacoordinated geometry in between a square pyramidal and a trigonal bipyramidal structure. Furthermore, the crystal structure of $\left[\mathrm{Hg}(\mathrm{HL})(\mathrm{SCN})_{2}\right]$ evidenced the formation of two types of $\mathrm{Hg} \cdot \cdots \mathrm{N}$ spodium bonds formed with the nitrogen atoms of the 3-Py and SCN ligand of other symmetry related units. These $\mathrm{Hg} \cdots \mathrm{N}$ spodium bonds enlarge the coordination environment of $\mathrm{Hg}(\mathrm{II})$ to a highly distorted pentagonal bipyramid and form a 1D zig-zag-like polymeric chain. By considering all the $\mathrm{Hg} \cdots \mathrm{N}$ spodium and $\mathrm{N}-\mathrm{H} \cdots \mathrm{N}$ hydrogen bonds, besides $\pi \cdots \pi$ interactions involving pyridine rings, a supramolecular 2D layer is formed with a binodal 3,4-connected hcb topology. According to the Hirshfeld surface analysis, the crystal packing of $\left[\mathrm{Hg}(\mathrm{HL})(\mathrm{SCN})_{2}\right]$ is mainly characterized by intermolecular $\mathrm{H} \cdots \mathrm{H}, \mathrm{H} \cdots \mathrm{C}, \mathrm{H} \cdots \mathrm{N}$ and $\mathrm{H} \cdots \mathrm{S}$ contacts, followed by less important $\mathrm{H} \cdots \mathrm{O}$, $\mathrm{C} \cdots \mathrm{C}, \mathrm{C} \cdots \mathrm{N}, \mathrm{N} \cdots \mathrm{S}$ and $\mathrm{Hg} \cdots \mathrm{N}$ contacts. In conclusion we have conceived the crucial role of the $\mathrm{Hg}$ (II)-derived spodium bonds on the supramolecular crystal packing of complex $\left[\mathrm{Hg}(\mathrm{HL})(\mathrm{SCN})_{2}\right]$, and of their dominant role in the formation of an extended structure, which has been confirmed by DFT calculations and a combination of QTAIM and NCIPlot study. This energetic analysis evidences a crucial role of spodium bonding interactions in the formation of the 2D supramolecular polymer in $\left[\mathrm{Hg}(\mathrm{HL})(\mathrm{SCN})_{2}\right]$. We hope that our findings might be of value for researchers when screening an appropriate combination of principal and auxiliary ligands in the design of new metal-organic extended structures.

\section{Declaration of Competing Interest}

The authors declare that they have no known competing financial interests or personal relationships that could have appeared to influence the work reported in this paper.

\section{Acknowledgements}

This work has been partially supported by the Fundação para a Ciência e a Tecnologia (FCT) 2020-2023 multiannual funding to Centro de Quimica Estrutural (project UIDB/00100/2020). AVG acknowledges the FCT and Instituto Superior Técnico (DL 57/2016 and L 57/2017 Program, Contract no: IST-ID/110/2018). This research was partially funded by MICIU/AEI, grant number CTQ2017-85821-R, FEDER funds.

\section{Appendix A. Supplementary data}

Supplementary data to this article can be found online at https://doi. $\operatorname{org} / 10.1016 /$ j.ica.2021.120279.

\section{References}

[1] P. Hobza, K. Müller-Dethlefs, Noncovalent interactions. Theory and Experiment, RSC Theoretical and Computational Chemistry Series, Royal Society of Chemistry, Cambridge, UK, 2010.

[2] J.P. Sauvage, P. Gaspard, From Noncovalent Assemblies to Molecular Machines, Wiley-VCH, Weinheim, Germany, 2011.

[3] S. Scheiner, Noncovalent Forces, Springer, Cham, Switzerland, 2015.

[4] A.M. Maharramov, K.T. Mahmudov, M.N. Kopylovich, A.J.L. Pombeiro, Noncovalent Interactions in the Synthesis and Design of New Compounds, John and Wiley and Sons, Hoboken, NJ, USA, 2016.

[5] J.D. van der Waals, On the continuity of the gaseous and liquid state, Doctoral Dissertation, Leiden, the Netherlands, 1873.

[6] J.D. Watson, F.H.C. Crick, Molecular structure of nucleic acids: a structure for deoxyribose nucleic acid, Nature 171 (1953) 737-738.

[7] K.E. Riley, P. Hobza, On the importance and origin of aromatic interactions in chemistry and biodisciplines, Acc. Chem. Res. 46 (2013) 927-936.

[8] P. Hobza, R. Zahradník, Intermolecular interactions between medium-sized systems. Nonempirical and empirical calculations of interaction energies. Successes and failures, Chem. Rev. 88 (1988) 871-897.

[9] K. Müller-Dethlefs, P. Hobza, Noncovalent interactions: a challenge for experiment and theory, Chem. Rev. 100 (2000) 143-168.

[10] C. Janiak, A critical account on $\pi-\pi$ stacking in metal complexes with aromatic nitrogen-containing ligands, J. Chem. Soc., Dalton Trans. (2000) 3885-3896.

[11] J. Ran, M.W. Wong, Saturated hydrocarbon-benzene complexes: theoretical study of cooperative $\mathrm{CH} / \pi$ interactions, J. Phys. Chem. A 110 (2006) 9702-9709.

[12] P. Hobza, R. Zahradník, K. Müller-Dethlefs, THE WORLD OF NON-COVALENT INTERACTIONS: 2006, Collect. Czech. Chem. Commun. 71 (2006) 443-531.

[13] K.E. Riley, M. Pitonák, P. Jurećka, P. Hobza, Stabilization and structure calculations for noncovalent interactions in extended molecular systems based on wave function and density functional theories, Chem. Rev. 110 (2010) 5023-5063.

[14] K.S. Kim, S. Karthikeyan, N.J. Singh, How Different are aromatic $\pi$ interactions from aliphatic $\pi$ interactions and non- $\pi$ stacking interactions? J. Chem. Theory Comput. 7 (2011) 3471-3477.

[15] L.M. Salonen, M. Ellermann, F. Diederich, Aromatic rings in chemical and biological recognition: energetics and structures, Angew. Chem., Int. Ed. 50 (2011) 4808-4842.

[16] S.E. Wheeler, Understanding substituent effects in noncovalent interactions involving aromatic rings, Acc. Chem. Res. 46 (2013) 1029-1038.

[17] A.S. Mahadevi, G.N. Sastry, Cooperativity in noncovalent interactions, Chem. Rev. 116 (2016) 2775-2825.

[18] J. Řezáč, P. Hobza, Benchmark calculations of interaction energies in noncovalent complexes and their applications, Chem. Rev. 116 (2016) 5038-5071.

[19] F. Biedermann, H.-J. Schneider, Experimental binding energies in supramolecular complexes, Chem. Rev. 116 (2016) 5216-5300.

[20] A. Bauzá, T.J. Mooibroek, A. Frontera, Tetrel bonding interactions, Chem. Rec. 16 (2016) 473-487.

[21] R. Thakuria, N.K. Nath, B.K. Saha, The nature and applications of $\pi-\pi$ interactions: a perspective, Cryst. Growth Des. 19 (2019) 523-528.

[22] A. Bauzá, S.K. Seth, A. Frontera, Tetrel bonding interactions at work: impact on tin and lead coordination compounds, Coord. Chem. Rev. 384 (2019) 107-125.

[23] B. Silvi, E. Alikhani, H. Ratajczak, Towards an unified chemical model of secondary bonding, J. Mol. Model. 26 (2020) 62.

[24] S. Scheiner, M. Michalczyk, W. Zierkiewicz, Coordination of anions by noncovalently bonded $\sigma$-hole ligands, Coord. Chem. Rev. 405 (2020), 213136.

[25] I. Alkorta, J. Elguero, A. Frontera, Not only hydrogen bonds: other noncovalent interactions, Crystals 10 (2020) 180.

[26] R.M. Gomilla, A. Frontera, Charge assisted halogen and pnictogen bonds: insights from the Cambridge Structural Database and DFT calculations, CrystEngComm 22 (2020) 7162-7169.

[27] P. Politzer, J.S. Murray, T. Clark, Halogen bonding and other $\sigma$-hole interactions: a perspective, Phys. Chem. Chem. Phys. 15 (2013) 11178-11189.

[28] P. Politzer, J.S. Murray, T. Clark, $\sigma$-Hole bonding: a physical interpretation, in: P. Metrangolo, G. Resnati (Eds.), Halogen Bonding I: Impact on Materials Chemistry and Life Sciences, Springer International Publishing, 2015, pp. 19-42.

[29] P. Politzer, J.S. Murray, T. Clark, G. Resnati, The $\sigma$-hole revisited, Phys. Chem. Chem. Phys. 19 (2017) 32166-32178. 
[30] A. Bauzá, I. Alkorta, J. Elguero, T.J. Mooibroek, A. Frontera, Spodium bonds: noncovalent interactions involving group 12 elements, Angew. Chem., Int. Ed. 59 (2020) 17482-17487.

[31] R.J. Kuppler, D.J. Timmons, Q.-R. Fang, J.-R. Li, T.A. Makal, M.D. Young, D. Yuan, D. Zhao, W. Zhuang, H.-C. Zhou, Potential applications of metal-organic frameworks, Coord. Chem. Rev. 253 (2009) 3042-3066.

[32] C. Janiak, J.K. Vieth, MOFs, MILs and more: concepts, properties and applications for porous coordination networks (PCNs), New J. Chem. 34 (2010) 2366-2388.

[33] N.N. Adarsh, P. Dastidar, Coordination polymers: what has been achieved in going from innocent 4,4'-bipyridine to bis-pyridyl ligands having a non-innocent backbone? Chem. Soc. Rev. 41 (2012) 3039-3060.

[34] M.P. Suh, H.J. Park, T.K. Prasad, D.W. Lim, Hydrogen storage in metal-organic frameworks, Chem. Rev. 112 (2012) 782-835.

[35] H. Wu, Q. Gong, D.H. Olson, J. Li, Commensurate adsorption of hydrocarbons and alcohols in microporous metal organic frameworks, Chem. Rev. 112 (2012) 836-868.

[36] R.J. Kuppler, D.J. Timmons, Q.R. Fang, J.R. Li, T.A.N. Stock, S. Biswas, Synthesis of metal-organic frameworks (MOFs): routes to various MOF topologies, morphologies, and composites, Chem. Rev. 112 (2012) 933-969.

[37] G. Mahmoudi, D.A. Safin, M.P. Mitoraj, M. Amini, M. Kubicki, T. Doert, F. Locherer, M. Fleck, Anion-driven tetrel bond-induced engineering of lead(II) architectures with N'-(1-(2-pyridyl)ethylidene)nicotinohydrazide: experimental and theoretical findings, Inorg. Chem. Front. 4 (2017) 171-182.

[38] G. Mahmoudi, A.A. Khandar, J. White, M.P. Mitoraj, H.S. Jena, P. Van Der Voort, N. Qureshi, A.M. Kirillov, K. Robeyns, D.A. Safin, Polar protic solvent-trapping polymorphism of the $\mathrm{Hg}^{\mathrm{II}}$-hydrazone coordination polymer: experimental and theoretical findings, CrystEngComm 19 (2017) 3017-3025.

[39] G. Mahmoudi, A.V. Gurbanov, S. Rodríguez-Hermida, R. Carballo, M. Amini, A. Bacchi, M.P. Mitoraj, F. Sagan, M. Kukułka, D.A. Safin, Ligand-driven coordination sphere-induced engineering of hybride materials constructed from $\mathrm{PbCl}_{2}$ and Bis-pyridyl organic linkers for single component light emitting phosphors, Inorg. Chem. 56 (2017) 9698-9709.

[40] G. Mahmoudi, E. Zangrando, M.P. Mitoraj, A.V. Gurbanov, F.I. Zubkov, M. Moosavifar, I.A. Konyaeva, A.M. Kirillov, D.A. Safin, Extended lead(II) architectures engineered via tetrel bonding interactions, New J. Chem. 42 (2018) 4959-4971.

[41] F.A. Afkhami, G. Mahmoudi, F. Qu, A. Gupta, E. Zangrando, A. Frontera, D. A. Safin, Supramolecular architecture constructed from the hemidirected lead(II) complex with N'-(4-hydroxybenzylidene)isonicotinohydrazide, Inorg. Chim. Acta 502 (2020), 119350

[42] F.A. Afkhami, G. Mahmoudi, F. Qu, A. Gupta, M. Köse, E. Zangrando, F.I. Zubkov, I. Alkorta, D.A. Safin, Supramolecular lead(II) architectures engineered by tetrel bonds, CrystEngComm 22 (2020) 2389-2396.

[43] B. Ay, E. Yildiz, O. Şahin, G. Mahmoudi, M. Kubicki, V. Perumal, J. Percino, B. Miroslaw, D.A. Safin, Novel lanthanide(III) complex $\left[\mathrm{LaL}_{2}\left(\mathrm{NO}_{3}\right)\left(\mathrm{H}_{2} \mathrm{O}\right)_{2}\right] \cdot 5 \mathrm{H}_{2} \mathrm{O}$ with 2-pyridine carboxaldehyde isonicotinoyl hydrazine exhibiting a $3 \mathrm{D}$ supramolecular topology 3,6T49, J. Mol. Struct. 1212 (2020), 128151.

[44] J.D. Velásquez, G. Mahmoudi, E. Zangrando, B. Miroslaw, D.A. Safin, J. Echeverría Non-covalent interactions induced supramolecular architecture of $\mathrm{Hg}(\mathrm{NCS})_{2}$ with 3-pyridinecarbaldehyde nicotinoylhydrazone, Inorg. Chim. Acta 509 (2020), 119700.

[45] G. Mahmoudi, F.A. Afkhami, A. Kennedy, F.I. Zubkov, E. Zangrando, A.M. Kirillov, E. Molins, M.P. Mitoraj, D.A. Safin, Lead(II) coordination polymers driven by pyridine-hydrazine donors: from anion-guided self-assembly to structural features, Dalton Trans. 49 (2020) 11238-11248.

[46] G. Mahmoudi, M. Abedi, S.E. Lawrence, E. Zangrando, M.G. Babashkina, A. Klein, A. Frontera, D.A. Safin, Tetrel bonding and other non-covalent interactions assisted supramolecular aggregation in a new $\mathrm{Pb}$ (II) complex of an isonicotinohydrazide, Molecules 25 (2020) 4056.

[47] G. Mahmoudi, F.A. Afkhami, E. Zangrando, W. Kaminsky, A. Frontera, D.A. Safin, A supramolecular 3D structure constructed from a new metal chelate selfassembled from $\mathrm{Sn}(\mathrm{NCS})_{2}$ and phenyl(pyridin-2-yl)methylenepicolinohydrazide, J. Mol. Struct. 49 (2020), 129188.

[48] G. Mahmoudi, M. Kubicki, D. Choquesillo-Lazarte, B. Miroslaw, E.V. Alexandrov, P. N. Zolotarev, A. Frontera, D.A. Safin, Supramolecular architectures of Mn(NCS) complexes with N'-(1-(pyridin-4-yl)ethylidene)picolinohydrazide and N'-(phenyl (pyridin-4-yl)methylene)isonicotinohydrazide, Polyhedron 190 (2020), 114776.

[49] C.R. Groom, I.J. Bruno, M.P. Lightfoot, The Cambridge Structural Database, S.C. Ward, Acta Crystallogr. B 72 (2016) 171-179.

[50] Y. Hanifehpour, S. Khanalilou, E. Paknahad, S.W. Joo, M.H. Sadr, B. Soltani, J. Inorg. Organomet. Polym. 22 (2012) 1248-1253.

[51] Y. Hanifehpour, N. Saraei, S.M. Asl, S.W. Joo, Synthesis and structural characterization of two new nano-coordination compounds based on Mercury(II) NN Donor Schiff Base, J. Inorg. Organomet. Polym. 22 (2012) 1271-1278.

[52] A. Masoumi, M.S. Gargari, G. Mahmoudi, B. Miroslaw, B. Therrien, M. Abedi, P. Hazendonk, Structural diversity in mercury(II) coordination complexes with asymmetrical hydrazone-based ligands derived from pyridine, J. Mol. Struct. 1088 (2015) 64-69.

[53] G. Mahmoudi, A.A. Khandar, J.K. Zare, M.J. Białek, M.S. Gargari, M. Abedi, G. Barandika, D. Van Derveer, J. Mague, A. Masoumi, The role of hydrogen bonding on supramolecular assembly of the mercury coordination compounds and final structure influenced by solvent effect, Inorg. Chim. Acta 429 (2015) 1-14.

[54] G. Mahmoudi, A. Bauzá, A.V. Gurbanov, F.I. Zubkov, W. Maniukiewicz, A. Rodríguez-Diéguez, E. López-Torres, A. Frontera, The role of unconventional stacking interactions in the supramolecular assemblies of $\mathrm{Hg}$ (II) coordination compounds, CrystEngComm 18 (2016) 9056-9066.
[55] G. Mahmoudi, E. Zangrando, A. Bauzá, W. Maniukiewicz, R. Carballo, A. V. Gurbanovg, A. Frontera, Molecular and crystalline architectures based on $\mathrm{HgI}_{2}$ : from metallamacrocycles to coordination polymers, CrystEngComm 19 (2017) 3322-3330.

[56] G. Mahmoudi, J.K. Zarẹba, A. Bauzá, M. Kubicki, A. Bartyzel, A.D. Keramidas, L. Butusov, B. Mirosław, A. Frontera, Recurrent supramolecular motifs in discrete complexes and coordination polymers based on mercury halides: prevalence of chelate ring stacking and substituent effects, CrystEngComm 20 (2018) 1065-1076.

[57] G. Mahmoudi, A.A. Khandar, F.A. Afkhami, B. Miroslaw, A.V. Gurbanov, F. I. Zubkov, A. Kennedy, A. Franconetti, A. Frontera, Modulation of coordination in pincer-type isonicotinohydrazone Schiff base ligands by proton transfer, CrystEngComm 21 (2019) 108-117.

[58] Nonius. COLLECT. Nonius BV, Delft, The Netherlands, 2000.

[59] A.J.M. Duisenberg, L.M.J. Kroon-Batenburg, A.M.M. Schreurs, An intensity evaluation method: EVAL-14, J. Appl. Cryst. 36 (2003) 220-229.

[60] A. Altomare, G. Cascarano, C. Giacovazzo, A. Guagliardi, M.C. Burla, G. Polidori, M. Camalli, SIR92 - a program for automatic solution of crystal structures by direct methods, J. Appl. Cryst. 27 (1994) 435.

[61] G.M. Sheldrick, SHELXT - integrated space-group and crystal-structure determination, Acta Crystallogr. A 71 (2015) 3-8.

[62] M.J. Frisch, G.W. Trucks, H.B. Schlegel, G.E. Scuseria, M.A. Robb, J.R. Cheeseman, G. Scalmani, V. Barone, G.A. Petersson, H. Nakatsuji, X. Li, M. Caricato, A. Marenich, J. Bloino, B.G. Janesko, R. Gomperts, B. Mennucci, H.P. Hratchian, J.V. Ortiz, A.F. Izmaylov, J.L. Sonnenberg, D. Williams-Young, F. Ding, F. Lipparini, F. Egidi, J. Goings, B. Peng, A. Petrone, T. Henderson, D. Ranasinghe, V.G. Zakrzewski, J. Gao, N. Rega, G. Zheng, W. Liang, M. Hada, M. Ehara, K. Toyota, R. Fukuda, J. Hasegawa, M. Ishida, T. Nakajima, Y. Honda, O. Kitao, H. Nakai, T. Vreven, K. Throssell, J.A. Montgomery, Jr., J.E. Peralta, F. Ogliaro, M. Bearpark, J. J. Heyd, E. Brothers, K.N. Kudin, V.N. Staroverov, T. Keith, R. Kobayashi, J. Normand, K. Raghavachari, A. Rendell, J.C. Burant, S.S. Iyengar, J. Tomasi, M. Cossi, J.M. Millam, M. Klene, C. Adamo, R. Cammi, J.W. Ochterski, R.L. Martin, K. Morokuma, O. Farkas, J.B. Foresman, D.J. Fox, Gaussian 16 (Revision A.03), Gaussian Inc., Wallingford CT, 2016.

[63] S.B. Boys, F. Bernardi, The calculation of small molecular interactions by the differences of separate total energies. Some procedures with reduced errors, Mol. Phys. 19 (1970) 553-556.

[64] S. Grimme, J. Antony, S. Ehrlich, H. Krieg, A consistent and accurate ab initio parametrization of density functional dispersion correction (DFT-D) for the 94 elements H-Pu, J. Chem. Phys. 132 (2010), 154104.

[65] P. Manna, S.K. Seth, M. Mitra, S. Ray Choudhury, A. Bauzá, A. Frontera, S. Mukhopadhyay, Experimental and computational study of counterintuitive $\mathrm{ClO}_{4}^{-} \cdots \mathrm{ClO}_{4}^{-}$Interactions and the Interplay between $\pi^{+}-\pi$ and Anion $\cdots \pi^{+}$ Interactions, Cryst. Growth Des. 14 (2014) 5812-5821.

[66] M. Mirzaei, H. Eshtiagh-Hosseini, Z. Bolouri, Z. Rahmati, A. Esmaeilzadeh, A. Bauza, P. Ballester, M. Barceló-Oliver, J.T. Mague, B. Notash, A. Frontera, Rationalization of noncovalent interactions within six new $\mathrm{M}(\mathrm{II})$ /8-aminoquinoline supramolecular complexes (M(II) = Mn, Cu, and Cd): a combined experimental and theoretical DFT study, Cryst. Growth Des. 15 (2015) 1351-1361.

[67] R.F.W. Bader, A universal indicator of bonded interactions, J. Phys. Chem. A 102 (1998) 7314-7323.

[68] J. Contreras-Garcia, E. Johnson, S. Keinan, R. Chaudret, J.-P. Piquemal, D. Beratan, W. Yang, NCIPLOT: a program for plotting non-covalent interaction regions, J. Chem. Theor. Comp. 7 (2011) 625-632.

[69] T.A. Keith, AIMAll (Version 19.02.13), TK Gristmill Software, Overland Park KS, USA, 2019 (aim.tkgristmill.com).

[70] K. Nakamoto, Infrared and Raman Spectra of Inorganic and Coordination Compounds, part B, 5th edition, Wiley, N. Y., 1997, p. 116.

[71] A.W. Addison, R.T. Nageswara, J. Reedijk, J. Van Rijn, G.J. Verschoor, Synthesis, structure, and spectroscopic properties of copper(II) compounds containing nitrogen-sulphur donor ligands; the crystal and molecular structure of aqua[1,7bis(N-methylbenzimidazol-2'-yl)-2,6-dithiaheptane]copper(II) perchlorate, J. Chem. Soc., Dalton Trans (1984) 1349-1356.

[72] D.A. Safin, K. Robeyns, M.G. Babashkina, C.M.L. Vande Velde, Y. Filinchuk, Ligand-driven anion- $\pi$ interaction-induced silver(I) coordination chemistry, Cryst. Growth Des. 16 (2016) 3763-3770.

[73] S. Alvarez, P. Alemany, D. Casanova, J. Cirera, M. Llunell, D. Avnir, Shape maps and polyhedral interconversion paths in transition metal chemistry, Coord. Chem. Rev. 249 (2005) 1693-1708.

[74] V.A. Blatov, A.P. Shevchenko, D.M. Proserpio, Applied topological analysis of crystal structures with the program package topospro, Cryst. Growth Des. 14 (2014) 3576-3586.

[75] M.A. Spackman, D. Jayatilaka, Hirshfeld surface analysis, CrystEngComm 11 (2009) 19-32.

[76] M.A. Spackman, J.J. McKinnon, Fingerprinting intermolecular interactions in molecular crystals, CrystEngComm 4 (2002) 378-392.

[77] M.J. Turner, J.J. McKinnon, S.K. Wolff, D.J. Grimwood, P.R. Spackman, D. Jayatilaka, M.A. Spackman, CrystalExplorer17, University of Western Australia, 2017, http://hirshfeldsurface.net. 
[78] C. Jelsch, K. Ejsmont, L. Huder, The enrichment ratio of atomic contacts in crystals, an indicator derived from the Hirshfeld surface analysis, IUCrJ 1 (2014) 119-128.

[79] E. Espinosa, E. Molins, C. Lecomte, Hydrogen bond strengths revealed by

topological analyses of experimentally observed electron densities, Chem. Phys.

Lett. 285 (1998) 170-173.
[80] M. Karmakar, A. Frontera, S. Chattopadhyay, T.J. Mooibroek, A. Bauzá,

Intramolecular spodium bonds in Zn(II) complexes: insights from theory and experiment, Int. J. Mol. Sci. 21 (2020) 7091. 